\title{
An improved process for the preparation of tenofovir disoproxil fumarate
}

Darren L. Riley ${ }^{1,4}$, David R Walwyn ${ }^{2,4}$, Chris D Edlin ${ }^{3,4}$

${ }^{1}$ University of Pretoria, Department of Chemistry, Natural and Agricultural Sciences, 2 Lynnwood Road, Hatfield, 0002, Gauteng, South Africa

${ }^{2}$ Department of Engineering and Technology Management, University of Pretoria, Pretoria, South Africa

${ }^{3}$ Pharmaceutical Manufacturing Technology Centre, University of Limerick, Limerick, Republic of Ireland

${ }^{4}$ iThemba Pharmaceuticals, Modderfontein, 1645, Gauteng, South Africa

* Author to which correspondence should be addressed: E-mail darren.riley@up.ac.za 

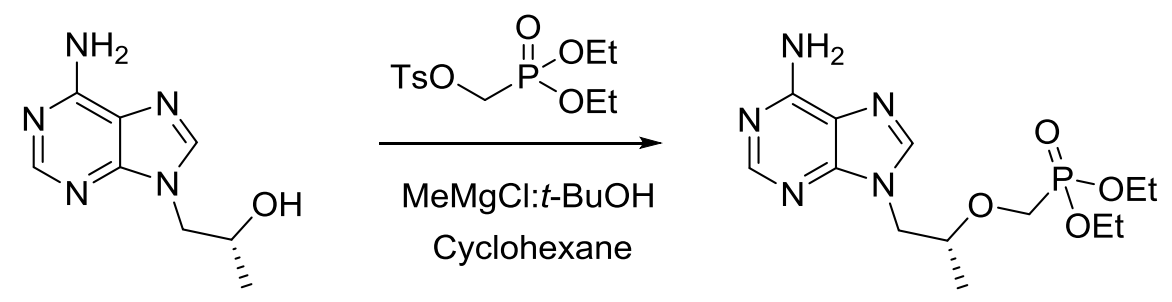

$85 \%$

Improved process for the preparation of tenofovir disoproxil fumarate 


\begin{abstract}
:
The current three-step manufacturing route for the preparation of tenofovir disoproxil fumarate (1) was assessed and optimized leading to a higher yielding, simpler and greener process. Key improvements in the process route include the refinement of the second stage through the replacement of the problematic magnesium tert-butoxide (MTB) with a 1:1 ratio of a Grignard reagent and tert-butanol. The development of a virtually solvent-free approach and the establishment of a work-up and purification protocol which allows the isolation of a pure diethyl phosphonate ester $(\mathbf{8})$.
\end{abstract}

Keywords: tenofovir, tenofovir disoproxil fumarate.

\title{
Introduction
}

Tenofovir disoproxil fumarate (1, TDF) and Tenofovir alafenamide fumarate (2, TAF) are pro-drugs of the nucleotide analogue reverse transcriptase inhibitor (NRTI) tenofovir (3, PMPA) developed for the treatment of HIV/AIDS and hepatitis B (figure 1). ${ }^{1-2}$ TDF (1) offers several key advantages over other mainstream NRTI's like zidovudine (AZT) and stavudine (d4T) including decreased rates of resistance development, longer half-life and less severe side effects and is currently one of the frontline treatments for the management of HIV/AIDS. ${ }^{3}$ TDF (1) is a current frontline drug used for the management of HIV/AIDS, the structurally related TAF (2) is currently undergoing phase 3 clinical trials, it has a greatly reduced dosage relative to that of TDF (1) and is viewed as being a potential future replacement for TDF $(\mathbf{1})^{2}$ 


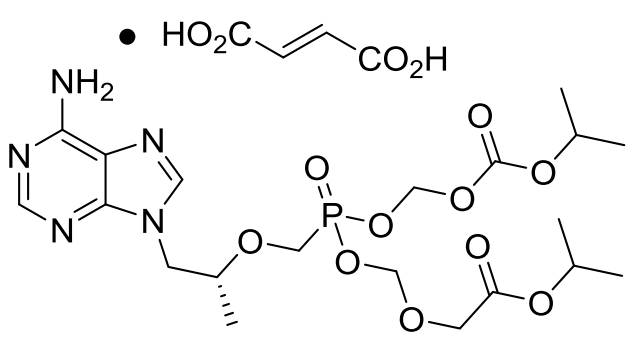

1

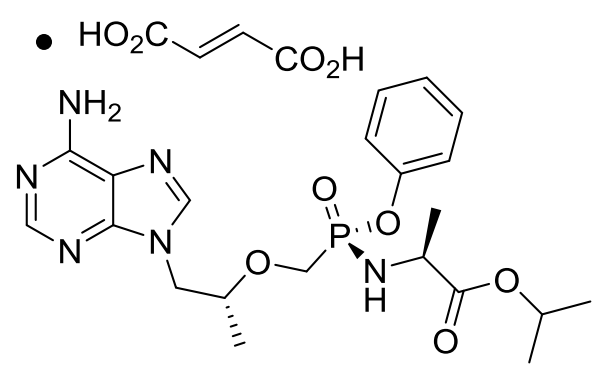

2

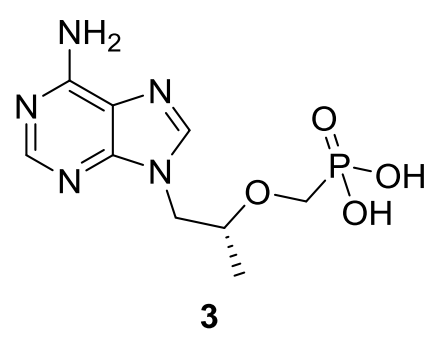

Figure 1: Structures of the reverse transcriptase inhibitors TDF and TAF.

TDF (1) and TAF (2) are currently manufactured from commercially available adenine (4) (scheme 1). The route to TDF involves an alkylation with $(R)-4$-methyl-1,3-dioxolan-2-one (5, RPA) to afford $(R)-9$ [2-(hydroxyl)propyl]adenine (6, HPA). The resulting HPA (6) is then alkylated with tosylated hydroxymethylphosphonate diester (7, DESMP) under basic conditions to afford diethyl phosphonate ester (8, PPA). The process typically does not facilitate the isolation of pure (8), instead the material is telescoped directly into stage 3 where hydrolysis of the diethyl phosphonate esters affords PMPA (3). TDF (1) can then be accessed by alkylative esterification and isolation as the fumaric salt (1). Alternatively TAF (2) can be accessed in a further three steps from PMPA (3). ${ }^{4}$ 
<smiles>C[C@@H](O)Cn1cnc2c(N)ncnc21</smiles>

6, HPA<smiles>CCOP(=O)(COc1ccccc1)OCC</smiles>

Stage $2 b$<smiles>CC(C)OC(=O)COCOP(=O)(CO[C@@H](C)Cn1cnc2c(N)ncnc21)OCOC(=O)OC(C)C</smiles>

1, TDF

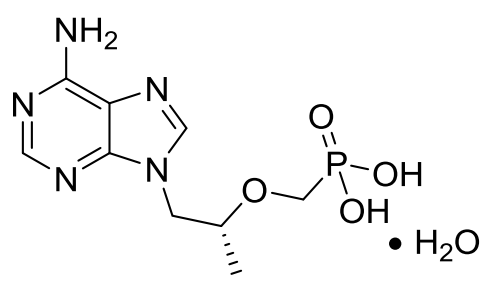

3, PMPA

Despite intensive research efforts, the development of a high yielding process route targeting TDF has to date not been fully realized ${ }^{6}$. This three stage process was originally patented by Gilead affording TDF in a $13 \%$ overall yield, ${ }^{5}$ this was more recently improved to $24 \%$ by the Clinton Health Access Initiative (CHAI), who were able to greatly improve stage 3 from $35 \%$ yield based upon PMPA (3) to $62 \%{ }^{6}$ In both instances it was not possible to isolate PPA (8) directly and crude material had to be telescoped to afford PMPA (3). The conversions of stage $2 \mathrm{~b}$ for the Gilead and CHAI routes at $50 \%$ and $90 \%$ are further compromised by the loss of material in this telescoping process. This report details an improved process route focused in particular on the chemistry, product isolation and purification of stage 2a.

\section{Stage 1}

HPA is commonly prepared by reaction of adenine (4) and $R$-propylene carbonate (5) at $120{ }^{\circ} \mathrm{C}$ in the presence of catalytic sodium hydroxide in DMF. The reaction is characterized by the formation of an 
unwanted regioisomer where addition occurs at the exocyclic- $\mathrm{NH}_{2}$ group, which typically accounts for 78 area $\%$ of the reaction mixture after completion. ${ }^{6}$ Recrystallization from $\mathrm{MeOH} / \mathrm{iPrOH}$ affords the desired HPA in 97-98 \% purity with 1-2 \% contamination with the unwanted NH-substituted regioisomer and a total $65 \%$ isolated yield. $^{6}$

An assessment was undertaken to investigate the choice of catalyst, solvent, catalyst loading and reaction time on the product yield. The insolubility of adenine in most solvents restricts the solvent choice to high boiling point polar aprotic solvents; DMF, NMP and DMSO and were screened against several catalysts including $\mathrm{NaOH}, \mathrm{KOH}, \mathrm{K}_{2} \mathrm{CO}_{3},(n-\mathrm{Bu})_{4} \mathrm{NHOH}, \mathrm{LiOH}$ and TsOH. All three solvent choices afforded $>90$ $\%$ conversions when used with $\mathrm{NaOH}, \mathrm{KOH}, \mathrm{K}_{2} \mathrm{CO}_{3}$ and $\mathrm{LiOH} . n-\mathrm{BuNOH}$ afforded a $95 \%$ conversion in DMSO, but this decreased to $72 \%$ and $55 \%$ when used in NMP and DMF respectively, and TsOH afforded only trace amounts of conversion when performed in DMSO and NMP. Unfortunately product recovery was poor when using DMSO or NMP as solvent. In contrast, when performed in DMF, HPA (6) can be readily precipitated from the reaction mixture.

The choice of catalyst greatly influenced the rate of reaction with $\mathrm{K}_{2} \mathrm{CO}_{3}>\mathrm{KOH}>>\mathrm{NaOH}>\mathrm{LiOH}$ (table 1) and when the temperature was increased to $153{ }^{\circ} \mathrm{C}$ in the presence of $10 \mathrm{~mol} \% \mathrm{KOH}$ in DMF $95 \%$ conversion was achieved in $\sim 30$ min (figure 2). Isolation of pure HPA using the CHAI work-up and purification protocol $^{6}$ then afforded a $65 \%$ yield of HPA with trace amounts of the unwanted regioisomer. $^{7}$

Table 1. Stage 1 conversion after 120 min using different catalysts ${ }^{a}$

\begin{tabular}{ccc}
\hline Entry & MTB substituent & Conversion (\%) \\
\hline 1 & $\mathrm{~K}_{2} \mathrm{CO}_{3}$ & 95 \\
2 & $\mathrm{KOH}$ & 84 \\
3 & $n-\mathrm{Bu}_{4} \mathrm{NOH}$ & 48
\end{tabular}


4

5

6
$\mathrm{NaOH}$

$\mathrm{LiOH}$

$\mathrm{TsOH}$
35

22

2

${ }^{a}$ Standard conditions: 6 ( 1 equiv), catalyst $\left(0.1\right.$ equiv), DMF $(1 \mathrm{M}) 120{ }^{\circ} \mathrm{C}$

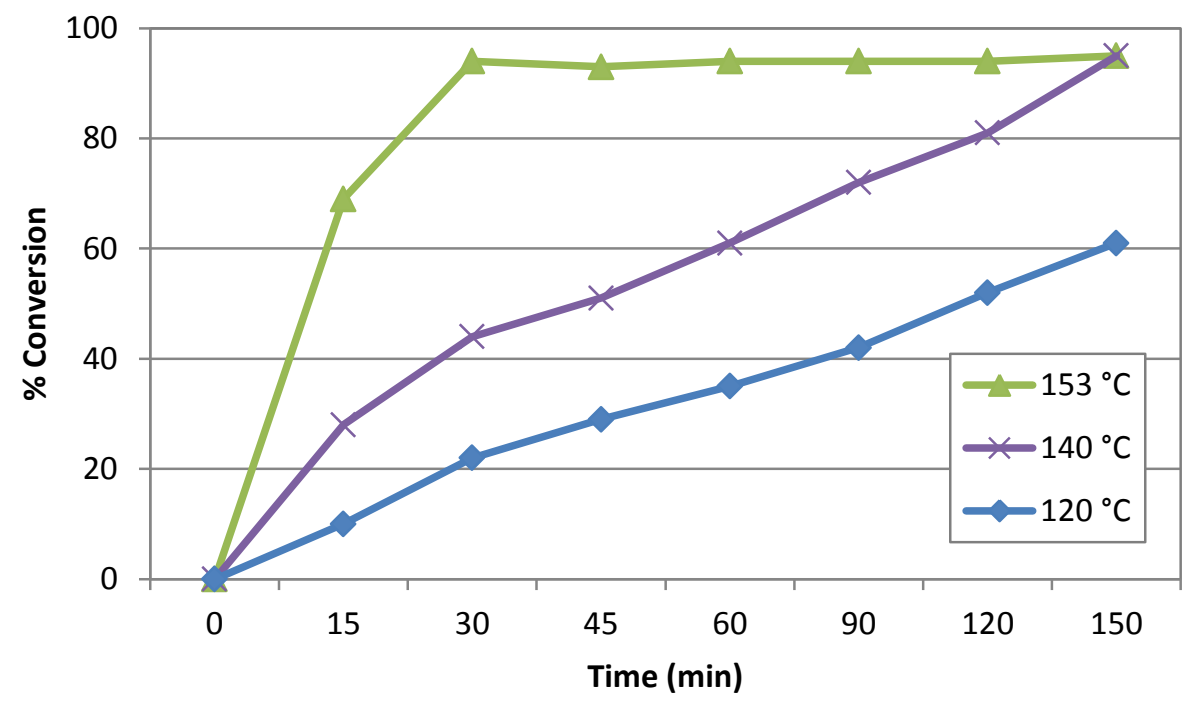

Figure 2.Stage 1 reaction profile at various temperatures, (conditions: 1 equiv. adenine, 0.1 equiv. KOH, DMF)

\section{Stage 2a}

To date one of the biggest challenges in stage 2 has been the choice of base used to facilitate the coupling of HPA (6) and DESMP (7). Magnesium tert-butoxide (MTB) has been commonly used affording high conversions in excess of $90 \% .^{6-7}$ In reality however the use of MTB is plagued by several factors; it is expensive, the transformation is highly dependent on the quality of the MTB and the magnesium salt byproducts makes the reaction work-up and purification difficult. ${ }^{6}$ In particular it is reported that the magnesium salt by-products form a sticky salt cake in which up to $15 \%$ of the PPA (8) formed is lost. ${ }^{6}$ The salts are highly hygroscopic, further complicating the telescoping into the stage $2 \mathrm{~b}$ hydrolysis. The 
latter is typically performed using moisture sensitive reagents like $\mathrm{TMSBr}$ or $\mathrm{TMSCl} / \mathrm{NaBr} .{ }^{6,8} \mathrm{The} \mathrm{CHAI}$ approach optimized this method to afford PMPA (3) at a conversion of $90 \%$ but an isolated yield of only $59 \%$ (98.4 \% HPLC purity) based upon HPA (6). ${ }^{6}$ Several alternative hindered alkoxide bases have been investigated but have only resulted in moderate conversions up to $68 \%$ for stage $2 \mathrm{a}^{6}{ }^{69}$ The use of strong bases including sodium amide, sodium hydride and di- $n$-butyl magnesium on their own or in combination with metal salts including magnesium chloride and magnesium acetate followed by hydrolysis have been reported with isolated yields of PMPA (3) in the range of 40-60\%. ${ }^{10}$ The use of a Grignard in the form of $n$-butyl magnesium chloride has also been reported followed by hydrobromic acid hydrolysis affording PMPA (3) in a moderate yield of $47 \% .{ }^{10}$ In all cases stage $2 \mathrm{a}$ has to be telescoped directly into stage $2 \mathrm{~b}$ out of necessity due to the difficulties associated with isolating pure PPA (8) from the reaction matrices. ${ }^{5-}$ ${ }^{6,10}$ Furthermore solvent choices are limited to undesirable high boiling point polar aprotics like DMSO, DMF and NMP, which in addition to being environmentally unfriendly make product isolation difficult. The CHAI route uses NMP for stage $2^{6}$ whereas the Gilead route and most other approaches use either DMF or DMSO. ${ }^{5,7-10}$

In order to optimize stage 2 we identified the following needs to find 1) a suitable lower-cost alternative to MTB, 2) a more suitable solvent and 3) the need for an efficient work-up and purification protocol allowing the isolation of pure PPA (8).

\section{Alternatives to magnesium tert-butoxide}

The use of MTB and a range of inorganic and organic bases not previously reported (table 2) confirmed the previously reported findings ${ }^{6-10}$ that MTB is the optimal base of choice affording excellent conversions (92\%, entries 1 and 2 in table 2$)$ when screened in DMSO or NMP. Sodium, potassium and lithium bases when screened either on their own of in combination with magnesium salts like magnesium chloride, bromide and acetate afforded no conversion, and Grignard reagents afforded poor conversions (entries 11 and 12 in table 2), 
Table 2. Selection of base for stage $2 \mathrm{a}^{a}$

\begin{tabular}{|c|c|c|c|}
\hline Entry & Base & Solvent & Conversion \\
\hline 1 & MTB (3 eq) & DMSO & $92 \%$ \\
\hline 2 & MTB (3 eq) & NMP & $92 \%$ \\
\hline 3 & $\mathrm{MgH}_{2}(3 \mathrm{eq})$ & NMP & $0 \%$ \\
\hline 4 & $\mathrm{Mg}(\mathrm{OAc})_{2}(1.1 \mathrm{eq}) / \mathrm{KO}^{t} \mathrm{Bu}(2.0 \mathrm{eq})$ & NMP & $0 \%$ \\
\hline 5 & $\mathrm{Mg}(\mathrm{OAc})_{2}(1.1 \mathrm{eq}) / \mathrm{NaO}^{\mathrm{t}} \mathrm{Bu}(2.0 \mathrm{eq})$ & NMP & $0 \%$ \\
\hline 6 & $\mathrm{MgBr}_{2}(0.54 \mathrm{eq}) / \mathrm{NaH}(1.8 \mathrm{eq})$ & $\mathrm{DMSO} / \mathrm{THF}$ & $0 \%$ \\
\hline 7 & $\mathrm{Mg}(\mathrm{OEt})_{2}(1 \mathrm{eq})$ & DMSO & $0 \%$ \\
\hline 8 & $\mathrm{MgCl}_{2}(1.05 \mathrm{eq}) / \mathrm{KO}^{\mathrm{t}} \mathrm{Bu}(1.05 \mathrm{eq})$ & DMSO & $0 \%$ \\
\hline 9 & $\mathrm{MgCl}_{2}(1.05 \mathrm{eq}) / \mathrm{NaO}^{\mathrm{t}} \mathrm{Bu}(1.05 \mathrm{eq})$ & DMSO & $0 \%$ \\
\hline 10 & $\mathrm{MgBr}_{2} . \mathrm{OEt}(2.3 \mathrm{eq}) / \mathrm{NaO}^{t} \mathrm{Bu}(1.05 \mathrm{eq})$ & DMSO & $0 \%$ \\
\hline 11 & $\operatorname{PhMgBr}(3$ eq) & $\mathrm{DMSO} / \mathrm{THF}$ & $6 \%$ \\
\hline 12 & $\mathrm{PhMgCl}(3$ eq) & $\mathrm{DMSO} / \mathrm{THF}$ & $28 \%$ \\
\hline 13 & $\mathrm{~K}_{2} \mathrm{CO}_{3}(3 \mathrm{eq})$ & DMSO & $0 \%$ \\
\hline 14 & $\mathrm{KOH}(3 \mathrm{eq})$ & DMSO & $0 \%$ \\
\hline 15 & $\mathrm{NaH}$ (3 eq) & DMSO & $0 \%$ \\
\hline 16 & $\mathrm{NaH}(3 \mathrm{eq})$ & $\mathrm{DMF}$ & $0 \%$ \\
\hline 17 & $\mathrm{NaO}^{t} \mathrm{Bu}(3 \mathrm{eq})$ & DMSO & $0 \%$ \\
\hline 18 & $\mathrm{NaO}^{\mathrm{t}} \mathrm{Bu}(3 \mathrm{eq})$ & NMP & $0 \%$ \\
\hline 19 & $\mathrm{TsOH}(3 \mathrm{eq})$ & NMP & $0 \%$ \\
\hline 20 & LiI (1.1 eq) & DMSO & $0 \%$ \\
\hline 21 & LiI (1.1 eq)/ $\mathrm{NaH}$ (1.1 eq) & DMSO & $0 \%$ \\
\hline \multicolumn{4}{|c|}{${ }^{a}$ Standard conditions: 6 ( 1 equiv), base (1.1-3 equiv), Solvent (1M), 7 (1.5 equiv), $75^{\circ} \mathrm{C}$} \\
\hline
\end{tabular}


The poor results from this initial screen prompted us to look at improving the reactivity by changing the tosyl group of DESMP (7) to a potentially more labile iodo-group. The results were even worse than in the initial screen with only sodium tert-butoxide affording trace amounts of product (entries 5-7 in table 3), and even more surprising was that MTB afford no conversion at all (entries 9 and 10 in table 3)

Table 3. Selection of base for stage 2 a when using $\mathrm{ICH}_{2} \mathrm{P}(\mathrm{O})(\mathrm{OEt})_{2}{ }^{a}$

\begin{tabular}{cccc}
\hline & MTB substituent & Solvent & Conversion \\
\hline 1 & $\mathrm{NaH}(1.7 \mathrm{eq})$ & $\mathrm{THF}$ & $0 \%$ \\
2 & $\mathrm{NaH}(1.7 \mathrm{eq})$ & $\mathrm{THF}$ & $0 \%$ \\
3 & $\mathrm{NaH}(1.05 \mathrm{eq})$ & $\mathrm{DMSO}$ & $0 \%$ \\
4 & $\mathrm{KO}^{\mathrm{t}} \mathrm{Bu}(1.05 \mathrm{eq})$ & $\mathrm{DMSO}$ & $0 \%$ \\
5 & $\mathrm{NaO}^{\mathrm{t}} \mathrm{Bu}(1.05 \mathrm{eq})$ & $\mathrm{DMSO}$ & Trace \\
6 & $\mathrm{NaO}^{\mathrm{t}} \mathrm{Bu}(2 \mathrm{eq})$ & $\mathrm{DMSO}$ & Trace \\
7 & $\mathrm{NaO}{ }^{\mathrm{t}} \mathrm{Bu}(3 \mathrm{eq})$ & $\mathrm{DMSO}$ & Trace \\
8 & $\mathrm{DBU}(3 \mathrm{eq})$ & $\mathrm{DMSO}$ & $0 \%$ \\
9 & $\mathrm{MTB}(3 \mathrm{eq})$ & $\mathrm{DMSO}$ & $0 \%$ \\
10 & $\mathrm{MTB}(1.05$ eq $) / \mathrm{AgO}(1.9$ eq $)$ & $\mathrm{DMSO}$ & $0 \%$ \\
\hline
\end{tabular}

We postulate that the divalent magnesium cation may be coordinating between the phosphonate oxygen and the oxygen(s) in the tosyl group of DESMP (7) to help promote the $\mathrm{S}_{\mathrm{N}} 2$ type displacement with HPA (6) (figure 3) this may also explain the observation that MTB works better than the corresponding monovalent sodium, lithium and potassium tert-butoxides. 


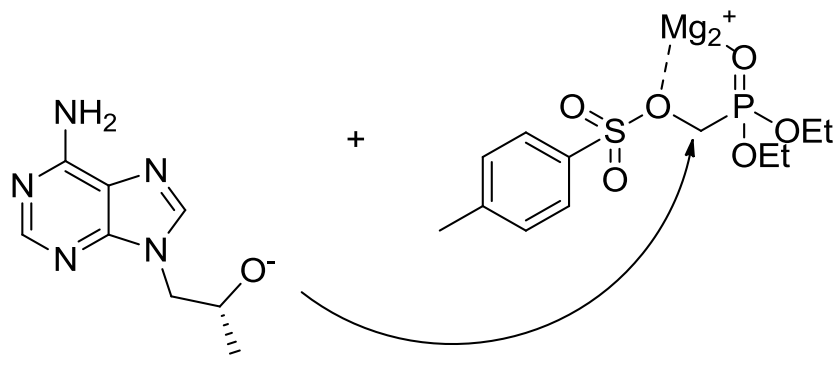

Figure 3. Proposed reaction of HPA and DESMP with co-ordination of magnesium (II) salts

These results suggested that alternative and more labile leaving groups would be limited to other exotic tosyl derivatives of the hydroxymethylphosphonate diester, and as a consequence we chose to persevere with DESMP (7) which has an established supply chain and rather focus on the optimization of the transformation using Grignard reagents as an alternative to MTB.

As alternative magnesium bases had proved ineffective in affording the transformation (table 2) it was decided to assess if the tert-butoxide groups in MTB were playing an important role by examining the effect of using phenyl magnesium chloride in the presence of tert-butanol. When performed in either DMSO or NMP the reactions showed the formation of both PPA (8) and to our surprise a half-hydrolyzed version of (8) (9, PPA-HH) (figure 4). An HPLC chromatogram shown in figure 5 shows HPA (6) eluting at $1.69 \mathrm{~min}$, followed by PPA-HH (9) and PPA (8) at 3.25 and $3.52 \mathrm{~min}$ respectively.<smiles>C[C@@H](O)Cn1cnc2c(N)ncnc21</smiles>

6

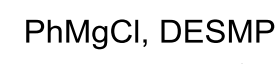

$t$-BuOH, NMP, $75^{\circ} \mathrm{C}$<smiles>CCOP(=O)(O)CO[C@@H](C)Cn1cnc2c(N)ncnc21</smiles>

9<smiles>CCOP(=O)(CO[C@@H](C)Cn1cnc2c(N)ncnc21)OCC</smiles>

8

Figure 4. Stage 2a when performed in the presence of a Grignard and tert-butanol. 


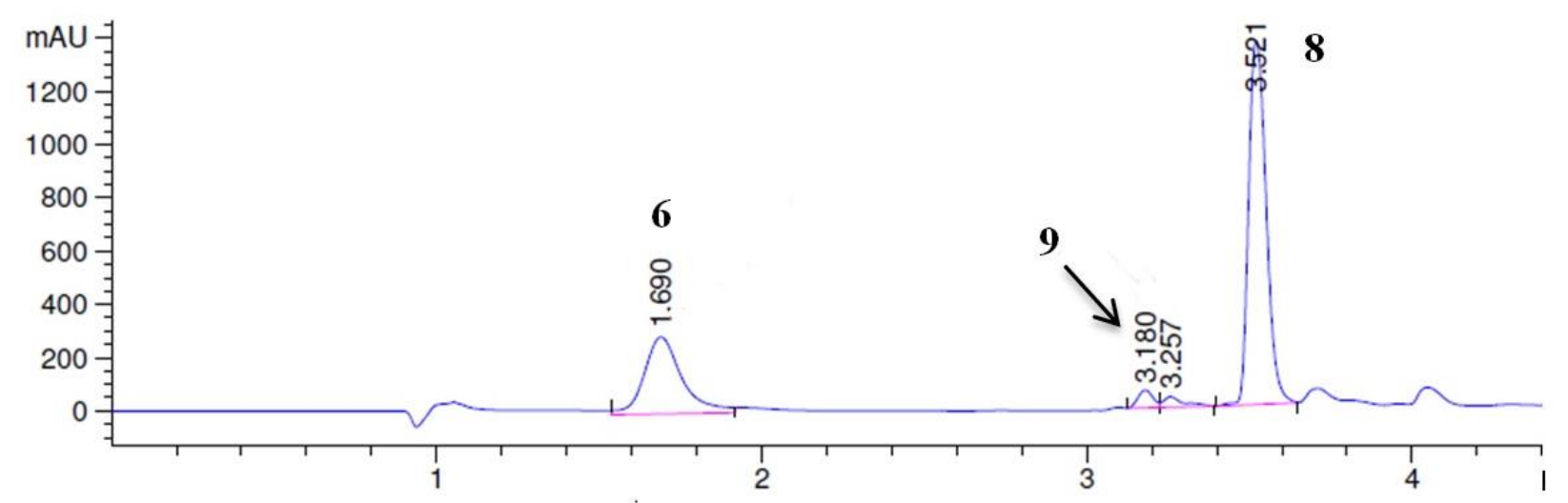

Figure 5. HPLC of reaction mixture for stage 2a

The formation of the half-hydrolyzed product in the absence of water is difficult to explain. We initially thought it may be due to the presence of unaccounted for water in the reaction solvents; however after employing stringent drying conditions to the solvents the phenomenon was still observed. Further thoughts were that there was partial hydrolysis occurring during the preparation of samples for HPLC analysis. This notion was however rejected when it was clearly observed that there was a steady increase in the amount of PPA-HH (9) as reaction time was increased suggesting an underlying reaction path which we were unable to rationalise. 
As PPA-HH (9) is only the partially hydrolyzed PPA (8) and stage 2 b requires complete hydrolysis to afford PMPA (3) we chose to assess the total conversion of the reaction to be the sum of the area\% for both PPA (8) and PPA-HH (9) (table 4)

Table 4. Effect of adding tert-BuOH on stage 2 a conversion ${ }^{a}$

\begin{tabular}{|c|c|c|c|c|c|c|}
\hline Entry & Conditions & Solvent & HPA (\%) & $\begin{array}{l}\text { PPA-HH } \\
(\%)\end{array}$ & PPA (\%) & $\begin{array}{c}\text { Total Conversion } \\
(\%)\end{array}$ \\
\hline 1 & $\mathrm{PhMgCl}(1 \mathrm{eq})$ & DMSO & 23 & 16 & 57 & 73 \\
\hline 2 & $\mathrm{PhMgCl}(2$ eq $)$ & DMSO & 3 & 46 & 30 & 76 \\
\hline 3 & $\mathrm{PhMgCl}$ (3 eq) & DMSO & 6 & 0 & 55 & 55 \\
\hline 4 & $\mathrm{PhMgCl}(1 \mathrm{eq})$ & NMP & 33 & 15 & 47 & 62 \\
\hline 5 & $\mathrm{PhMgCl}(2$ eq) & NMP & 20 & 42 & 15 & 57 \\
\hline 6 & $\mathrm{PhMgCl}(3$ eq) & NMP & 47 & 37 & 0 & 37 \\
\hline
\end{tabular}

In the absence of tert-butanol when using excess phenyl magnesium chloride in DMSO a maximum conversion of only $28 \%$ was observed (table 2 , entry 12 ). The addition of tert-butanol however greatly improved the overall conversion of stage $2 \mathrm{~b}$ to $55 \%$ when using three equivalents of phenyl magnesium chloride (table 3, entry 3). Interestingly when the stoichiometric ratio of the Grignard was reduced to 2 and 1 equivalents respectively the conversions improved even more to $76 \%$ and $73 \%$ respectively (table 3, entries 1 and 2). When repeated in NMP a similar trend was observed (table 3, entries 4-6). DMSO afforded marginally better conversions; this was most likely due to improved solubility of the HPA in DMSO. Focus was placed on the use of NMP as a solvent. It was considered that the use of NMP afforded a better opportunity for the isolation of PPA (8) after stage 2a. 
Reaction concentration seemed to have little effect on the overall conversion and when performed in NMP within the range of $0.345-2 \mathrm{M}$ the conversions consistently ranged between 62 and $66 \%$ (table 5). Beyond 2M the solubility of HPA became a limiting factor.

Table 5. Effect of the reaction concentration on stage 2 a conversion ${ }^{a}$

\begin{tabular}{|c|c|c|c|c|}
\hline & Concentration (M) & PPA-HН (\%) & PPA (\%) & Total Conversion (\%) \\
\hline 1 & 0.345 & 15 & 47 & 62 \\
\hline 2 & 1 & 7 & 59 & 66 \\
\hline 3 & 2 & 7 & 55 & 62 \\
\hline
\end{tabular}

Assessment of the choice of Grignard reagent (table 6) showed that the reagent derived from chlorides afforded significantly better conversions than those derived from bromides with phenyl magnesium chloride and methyl magnesium chloride giving the highest conversions (62\% and $57 \%$ respectively). The conversion dropped off significantly when using a bulky Grignard like 2,2,6,6-tetramethylpiperidinylmagnesium chloride. We decided to focus the process optimisation using methyl magnesium chloride even though phenyl magnesium chloride afforded slightly better conversions as the methyl analogue was more atom-economical, cheaper to source and the reaction was marginally cleaner.

Table 6. Effect of the type of Grignard on stage 2a conversion ${ }^{a}$

\begin{tabular}{lllll}
\hline Grignard & HPA $(A \%)$ & PPA-HH (A\%) & PPA (A\%) & Total Conversion (A\%)*
\end{tabular}

\begin{tabular}{lcccc}
\hline $\mathrm{PhMgCl}$ & $34 \%$ & $7 \%$ & $55 \%$ & $62 \%$ \\
$\mathrm{PhMgBr}$ & $44 \%$ & $19 \%$ & $29 \%$ & $48 \%$ \\
$\mathrm{MeMgCl}$ & $8 \%$ & $13 \%$ & $44 \%$ & $57 \%$ \\
$\mathrm{MeMgBr}$ & $36 \%$ & $11 \%$ & $37 \%$ & $48 \%$
\end{tabular}




$\begin{array}{ccccc}\text { i-PrMgCl } & 38 \% & 9 \% & 46 \% & 55 \% \\ \begin{array}{c}2,2,6,6-\text { Tetramethyl- } \\ \text { piperidinylmagnesium } \\ \text { chloride }\end{array} & 63 \% & 5 \% & 26 \% & 31 \% \\ \end{array}$

${ }^{a}$ Standard conditions: 6 (1 equiv), Grignard (1 equiv), NMP $(2 \mathrm{M}), 7$ (1.5 equiv), $t$-BuOH (2 equiv), $75^{\circ} \mathrm{C}$

The process was further optimized in terms of reaction time; the reaction was monitored by LCMS every fifteen to twenty min for three hours (figure 6). At $75{ }^{\circ} \mathrm{C}$ the formation of PPA (8) began within 15 min and increased rapidly from 30 to $60 \mathrm{~min}$. The half-hydrolyzed product PPA-HH (9) only started forming after 45 min. The overall conversion to PPA (8) + PPA-HH (9) started to slow significantly after 105 min corresponding to a conversion of $\sim 60 \%$, thereafter a slow conversion of PPA (8) to PPA-HH (9) continued to be observed. When left for an extended period of time $(19 \mathrm{~h})$ the overall conversion increased to $74 \%$, of which $63 \%$ was PPA-HH (9) and only $11 \%$ remained as un-hydrolyzed PPA (8). Unfortunately significant amounts of unidentified impurities started to form after $3 \mathrm{~h}$. When performed at $120{ }^{\circ} \mathrm{C}$ conversions peaked at $72 \%$ after only 90 min but product decomposition started becoming a limiting factor, with significant decomposition observed after 120 min. A standard reaction temperature of $75^{\circ} \mathrm{C}$ was adopted for all further optimizations. 


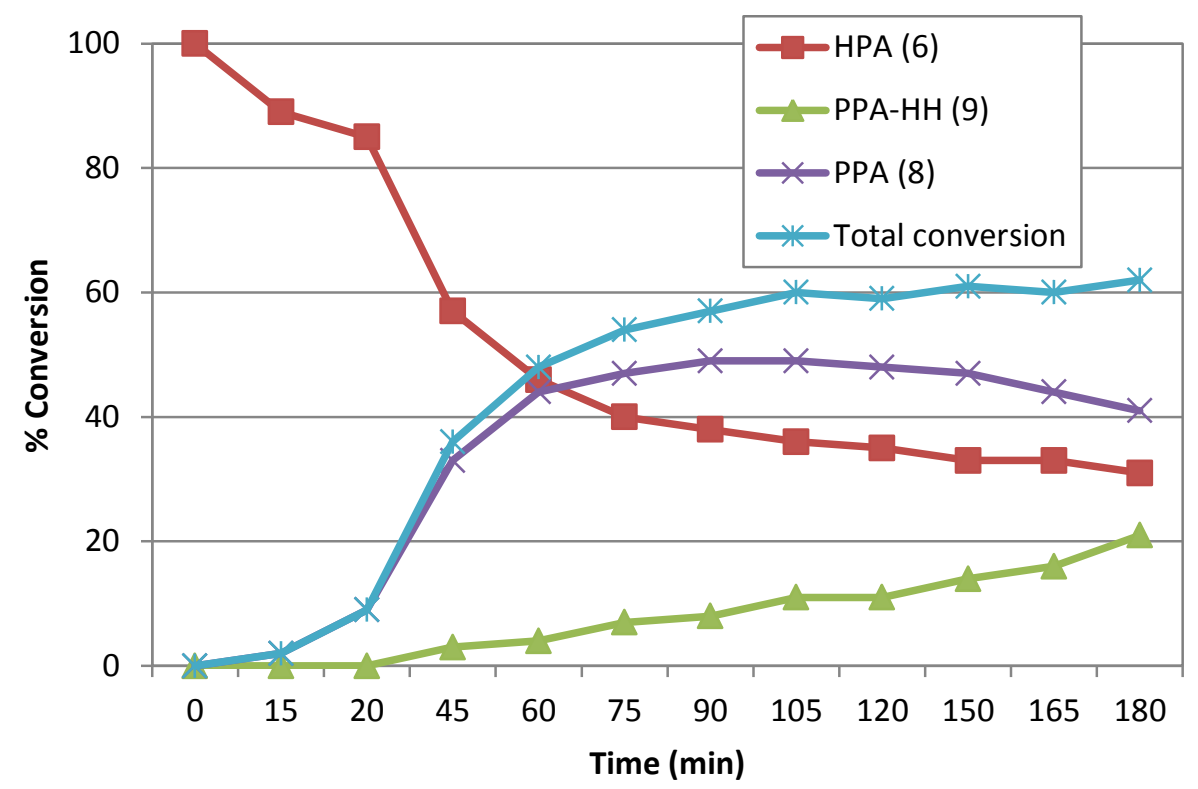

Figure 6. Reaction profile for stage 2a. (conditions: 1 equiv. MeMgCl, 1.5 equiv. DESMP, 2 equiv. $t$ BuOH, 2M NMP)

In an attempt to optimize the stoichiometric amounts of the various reagents and to improve the overall conversion it was decided to investigate the effects of changing the amount of DESMP (7), tert-butanol and methyl magnesium chloride relative to HPA.

In order to assess the effect of tert-butanol we screened the reaction using 0.5 to 2.5 equivalents of tertbutanol (figure 7). The results indicated that below 1 equivalent the overall conversion was low $(<40 \%)$, peaking at $78 \%$ for 1 equivalent of tert-butanol, and then steadily decreasing as the amount of tertbutanol was further increased. 


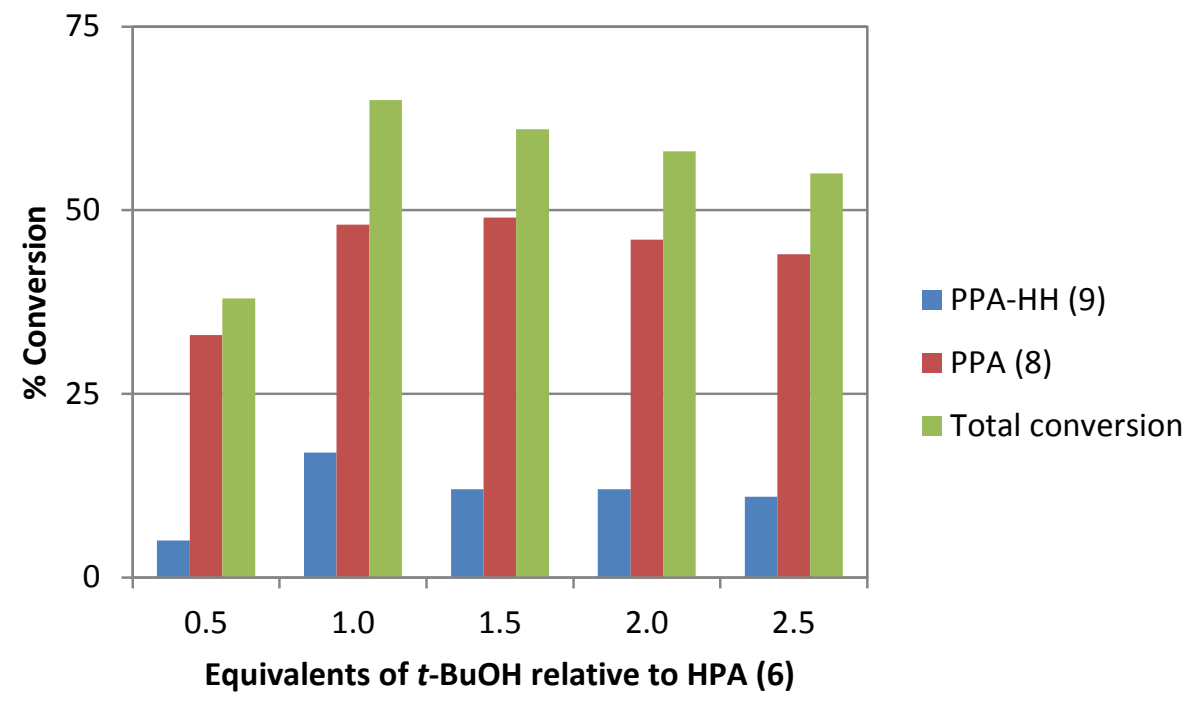

Figure 7. Effect of change the stoichiometric ratio of tert-BuOH relative to HPA. (conditions: 1 equiv. MeMgCl, 1.5 equiv. DESMP, 0.5-2.5 equiv. $t$-BuOH, 2M NMP)

Encouraged by the dramatic impact that the tert-butanol had on the reaction a number of alternative primary and secondary alcohols (figure 8) were screened. However tert-butanol was found to be the optimal choice with a conversion of $67 \%$; the other alcohols screened ranged from $13-43 \%$.

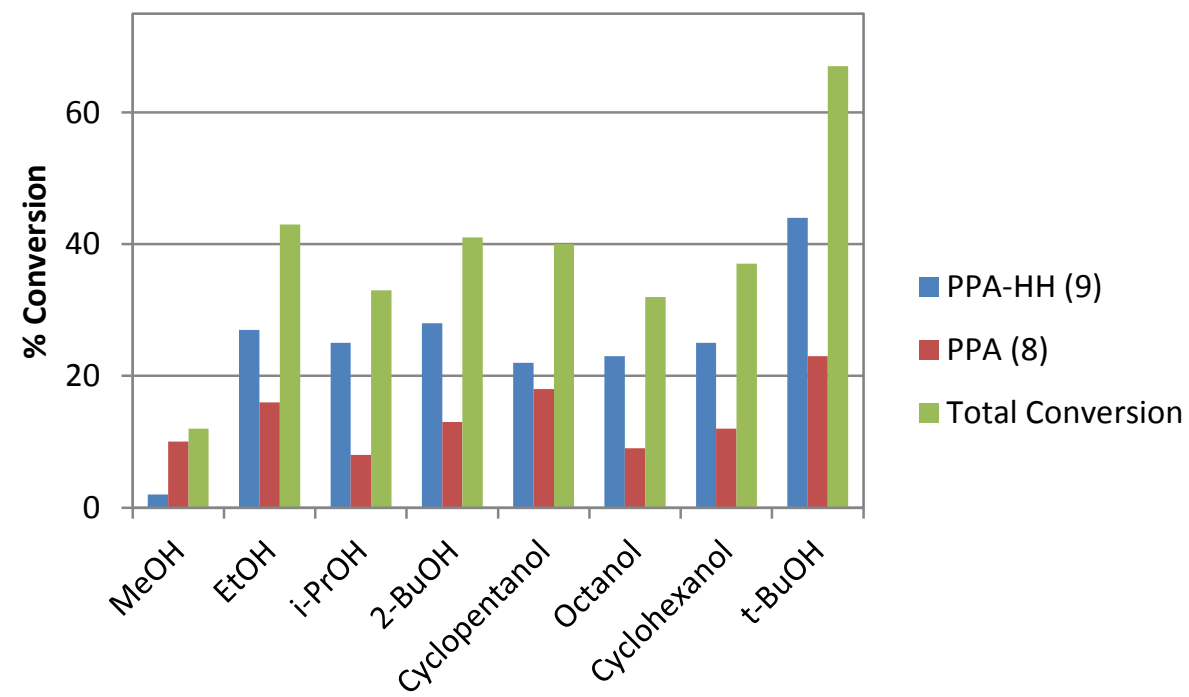

Figure 8. The effect of changing the alcohol on stage 2a. (conditions: 1 equiv. MeMgCl, 1.5-3.0 equiv. DESMP, 1.0 equiv. tert-BuOH, 2M NMP) 
The amount of DESMP used was screened in the range of 1.5-3.0 equivalents relative to HPA while maintaining the amount of tert-butanol at 1 equivalent. The results showed that conversion reached a maximum of (85-86\%) between 2.3 and 2.6 equivalents (figure 9). As a result, standard conditions were adopted to include the use 2.5 equivalents of DESMP (7). Under these conditions the amount of halfhydrolysed PPA (PPA-HH, 9) only represented 1.5-2.3\% of the total conversion.

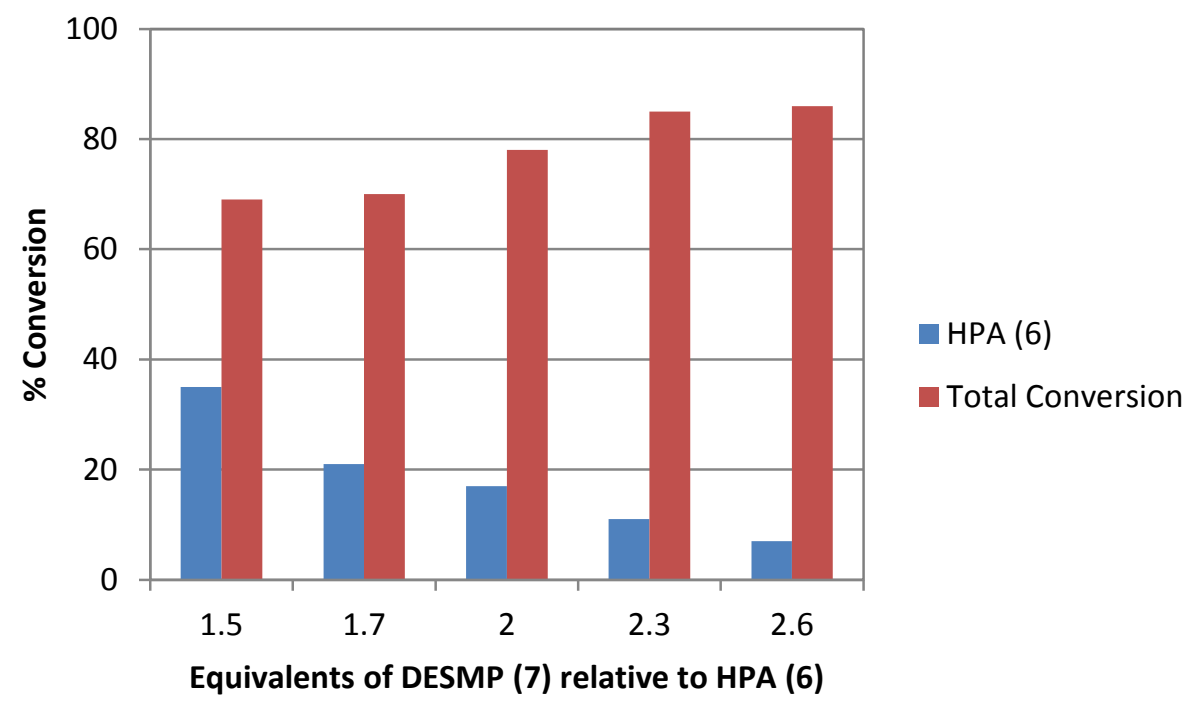

Figure 9: Stage 2a conversion using 1.5 to 3.0 equivalents of DESMP. (conditions: 1 equiv. MeMgCl, 1.5 equiv. $7,1.0$ equiv. alcohol, 2M NMP)

The initial Grignard screen indicated a reduction in conversion as the amount of Grignard increases with 1 equivalent relative to HPA (6) affording the highest conversion. An examination of the effect of using less than 1 equivalent of the Grignard revealed that conversion drops off dramatically with 0.75 equivalents affording $58 \%$ conversion and 0.5 equivalents $38 \%$ conversion. 
Having optimized the reaction in terms of time, stoichiometry of the various components relative to HPA (6) and choice of base and additives, the effect of changing the order of some of the process steps was studied. The standard procedure involved the preparation of a suspension of HPA (6) and tert-butanol in NMP, to which was added methyl magnesium chloride drop-wise, followed within 30 min by the dropwise addition of DESMP (7). We observed that if the DESMP (7) was introduced prior to the addition of the methyl magnesium chloride the process showed a slight drop in conversion from $86 \%$ to $80 \%$, and if the methyl magnesium chloride and the tert-butanol are pre-mixed prior to the addition to the HPA and DESMP (7) the conversion drops to $77 \%$.

\section{Solvent alternatives}

A goal of this research was to reduce the need for undesirable solvents. Unfortunately the insolubility of HPA severely limits the choice of solvents to that of high boiling point aprotic polar solvents like DMF, NMP and DMSO.

As the optimized process makes use of excess DESMP which itself is a liquid at ambient temperature, it was proposed that we could forgo the use of NMP and perform the reaction under solvent-free conditions. A typical approach was to suspend HPA and tert-butanol in DESMP followed by the drop-wise addition of methyl magnesium chloride at $0{ }^{\circ} \mathrm{C}$, thereafter heating the reaction to $75{ }^{\circ} \mathrm{C}$. Under these conditions a $77 \%$ conversion is observed. Unfortunately under the solvent-free conditions the reaction mixture becomes increasingly viscous over time eventually forming a thick, sticky residue which is difficult to stir and process, although at larger scale this problem could potentially be easily handled using an extruder or similar technique. To reduce the viscosity of the reaction we investigated the addition of a small quantity of a low-boiling point solvent that could easily be removed in vacuo after the reaction. Twelve solvents, five polar aprotic, two polar and five non-polar were screened (figure 10). The use of non-polar solvents afforded the highest conversions, the best being cyclohexane with a conversion of $85 \%$. 


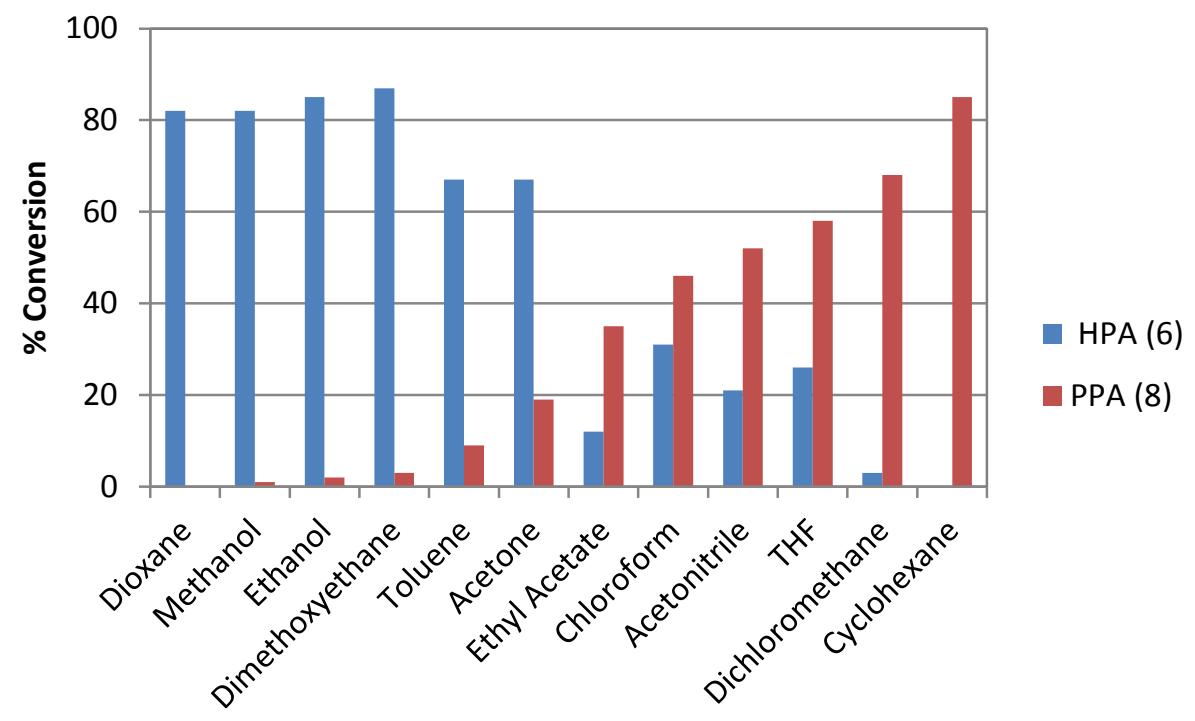

Figure 10: Stage 2a conversion when using different solvent to reduce reaction mixture viscosity (conditions: 6, 1 equiv, $\mathrm{MeMgCl}, 1$ equiv, $1 \mathrm{M}$ solvent, 7, 1.5 equiv, alcohol, 1 equiv, $75^{\circ} \mathrm{C}$ )

The co-solvent screen included the use of several solvents that are not compatible with Grignard's in the traditional sense of a solvent. Ethanol and methanol were investigated as we were interested in their effect as a potential solubilizing system which over time would react with the Grignard in an analogous manner to that of tert-butanol to form their respective magnesium bases. Unfortunately in both cases conversion was very poor. More interesting was the use of acetone which was highly efficient at reducing the reaction mixture viscosity. We postulated that it would react with the methyl magnesium chloride to form the tert-butoxide anion, which in turn would form a magnesium base as would have been the case if simply using tert-butanol on its own. As such we viewed acetone as being a green, easy to remove potential substitute for both the tert-butanol and NMP. Unfortunately conversion in the presence of tert$\mathrm{BuOH}$ was however poor $<20 \%$ and in light of having identified cyclohexane as an excellent co-solvent we abandoned this idea.

The use of cyclohexane as a solvent to reduce reaction mixture viscosity was further screened at $0.5 \mathrm{M}$ and $1 \mathrm{M}$. The process performed similarly at both concentrations (figure 11). At concentration greater 
than $1 \mathrm{M}$ reaction mixture viscosity made processing difficult. Furthermore the reaction proceeded with better conversion and showed fewer impurities if the tetrahydrofuran and cyclohexane were allowed to slowly boil off approximately $1 \mathrm{~h}$ after the addition of the DESMP.

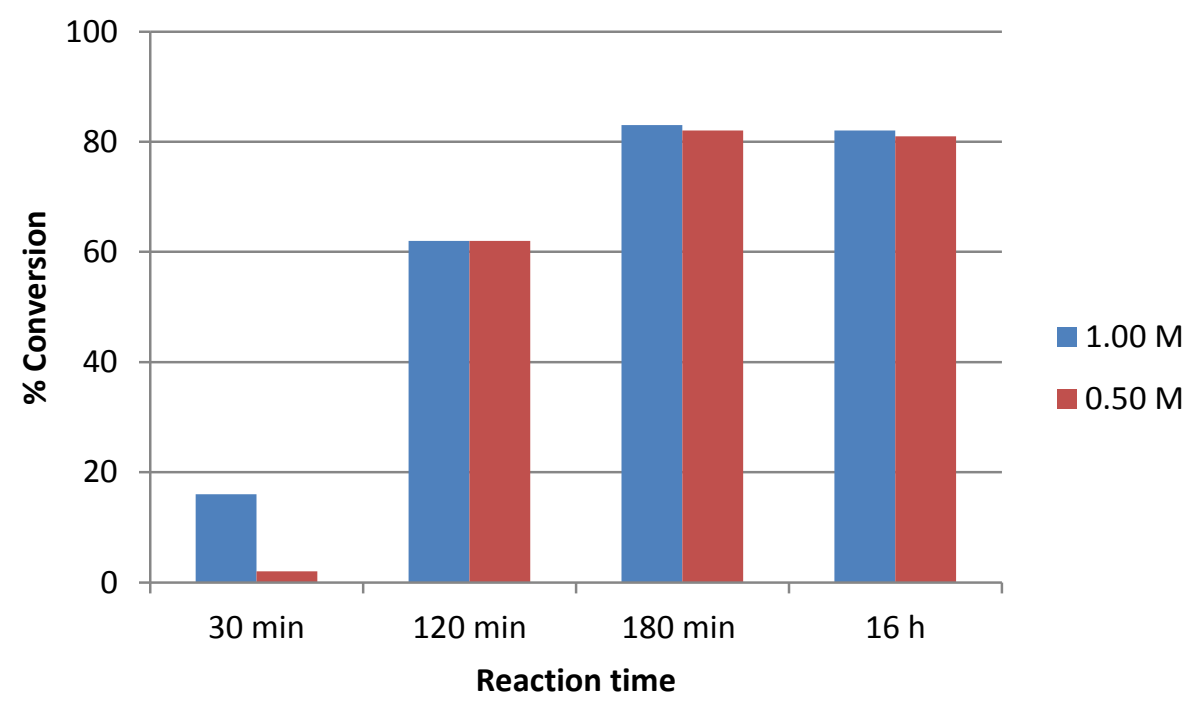

Figure 11: Stage 2a conversion when using cyclohexane at concentrations from $0.25 \mathrm{M}$ to $1 \mathrm{M}$. (conditions: 1 equiv. 6, 1 equiv. MeMgCl, 0.25-1 M cyclohexane, 1.5 equiv. DESMP, 1 equiv. $t$ $\mathrm{BuOH}, 75^{\circ} \mathrm{C}$ )

\section{Reaction work-up and product isolation}

The reaction work-up was continuously assessed during the optimizing phase of the project. Unfortunately in most cases little to no material could be isolated directly out of Stage 2a. Several attempts were made to purify the material including ion-exchange chromatography, recrystallization as a pure material, recrystallization as various salt forms, flash column chromatography and trituration with various solvent systems to no avail. The key issue seemed to be the use of NMP and DMSO as a solvent system both of which are not easily removed and are highly solubilizing of PPA (8). 
The development of the virtually "solvent-free" approach allowed us to develop a work-up and purification protocol that affords the isolation of pure PPA (8) in high yields. ${ }^{11}$ The work-up protocol (Scheme 2) involves solubilizing the solvent-free reaction mixture in water followed by continuous extraction into chloroform, allowing the removal the water soluble unreacted HPA and magnesium salts present at the end of the reaction. Acid extraction of the organic phase then facilitates the removal of organic soluble unreacted DESMP (7) and an additional unidentified DESMP (7) by-product. ${ }^{11}$ Basification of the aqueous phase to $\mathrm{pH} 11$ followed by extraction into dichloromethane allows the isolation of pure PPA $(\mathbf{8})$ in a $76 \%$ yield. ${ }^{12}$ Re-extraction of the basified aqueous layers under continuous conditions using dichloromethane followed by an acid-base extraction and final extraction into dichloromethane affords a further $9 \%$ recovery of PPA $(8)$ for a total recovery of $85 \%$ with a purity $94-$ $98 \%$ as determined by HPLC. ${ }^{12}$ 


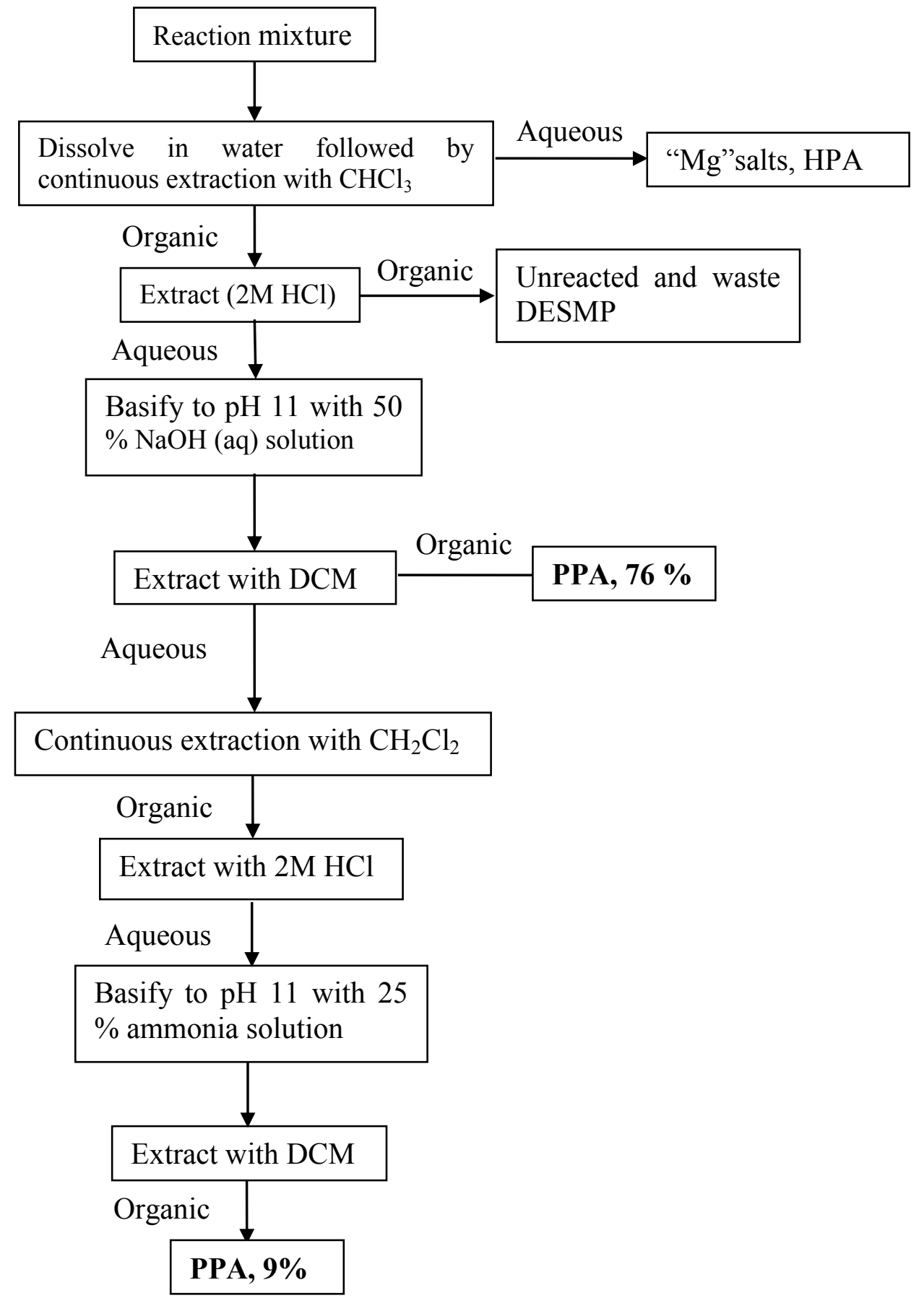

Scheme 2: Work-up protocol for the isolation of PPA (8)

Chloroform is a potential mutagen and is environmentally unfriendly; as such the use of chloroform is best avoided on scale if possible. Dichloromethane is often used as a replacement for chloroform on scale. 
Unfortunately when we attempted the process by replacing the chloroform in the first extractive process with dichloromethane and running the extraction for the same time $(24 \mathrm{~h})$ the overall yield of isolated PPA (8) fell to $55 \%$ after the first continuous extraction. A further $8 \%$ was isolated after the second extraction ( $63 \%$ total). Interestingly the use of chloroform or dichloromethane in the second extractive process showed no significant difference.

A further examination of the choice of potential extracting solvent was undertaken by assessment of the solubility of PPA (8) in various solvents by dissolving know quantities of PPA (8) in water and measuring the extent of extraction into organic solvents when shaken for $5 \mathrm{~min}$ (figure 12). Chloroform and dichloromethane performed. As the liquid-liquid extraction is continuous in nature, it is conceivable that a more desirable solvent like iso-propyl acetate or ethyl acetate could be used with an extended extraction time as both show reasonable ability to extract PPA $(8)$ from water.

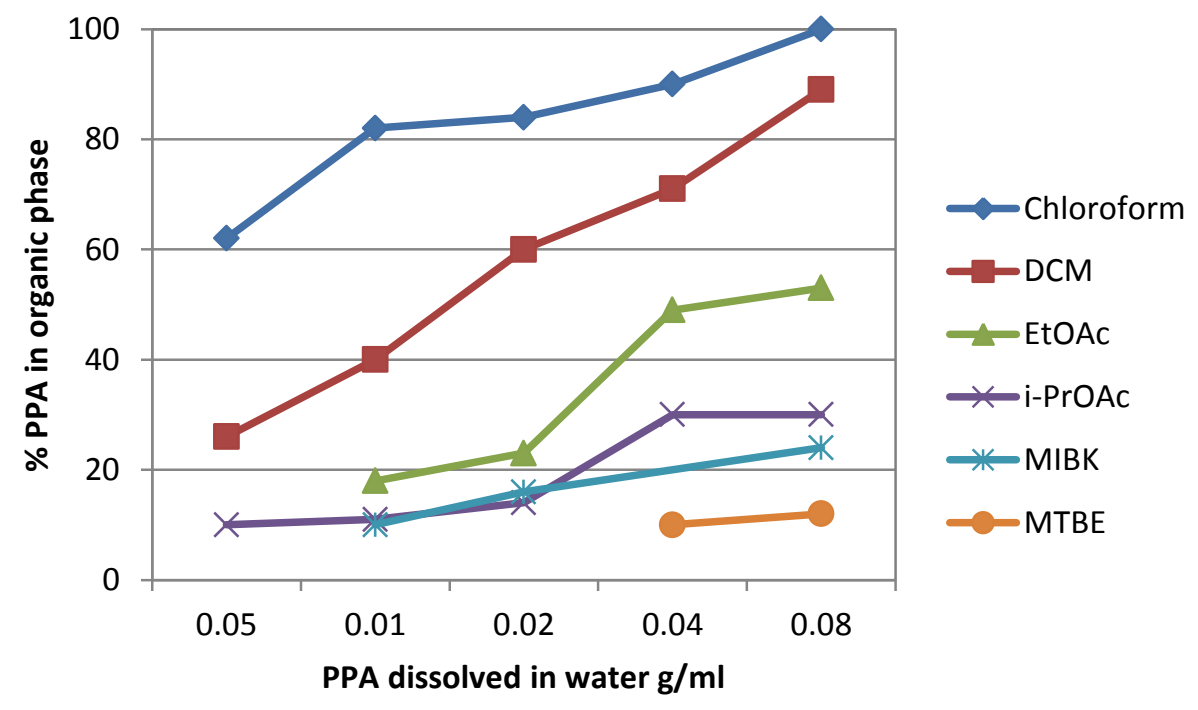

Figure 12: Percentage PPA in organic phase when portioned in water.

Under our conditions the chloroform, dichloromethane extractive process showed the best results. We were able to demonstrate this process on $0.3 \mathrm{~mol}$ scale, equating to the use of $58 \mathrm{~g}$ of HPA (6) affording a total of $87.6 \mathrm{~g}$ of PPA $(\mathbf{8})$ with a purity $>94 \% .^{12}$ 


\section{Stage 2b}

The hydrolysis of PPA can be achieved by treatment with $\mathrm{TMSCl} / \mathrm{NaBr}$ in NMP under anhydrous conditions, or alternatively by treatment under acidic conditions with either $\mathrm{HCl}(32 \%)$ or $\mathrm{HBr} / \mathrm{Acetic}$ Acid (33\%). In the first instance when using 3.5 equivalents of sodium bromide and 5.3 equivalents of TMSCl, PMPA (3) can be isolated in a $24 \%$ yield. In comparison if treated with $33 \% \mathrm{HBr} /$ Acetic acid (6.3 equivalents) PMPA (3) can be isolated in a $73 \%$ yield.

\section{Conclusion}

This work has developed several improvements to the process route for TDF (1). In stage 1 the alternative choice of catalyst dramatically improves the reaction rate, with potassium bases showing advantage over the currently utilized sodium bases. The route most significantly shows dramatic improvements to stage 2a by replacing the problematic MTB and undesirable solvents like DMF and NMP. When coupled with the improvements reported by CHAI for Stage 3, this new route shows a comparable overall yield of 23.0 $\%$ versus $24.3 \%$ for the CHAI route ${ }^{6}$ and a significant improvement over other leading routes by Laurus Labs $^{7 \mathrm{~b}}$ and Gilead ${ }^{5}$ (19\% and $13 \%$ respectively). Key findings were that the use of a Grignard in combination with tert-butanol affords good conversions for stage 2a, that the process could be performed under virtually solvent-free conditions and the pure PMPA (3) can be isolated through suitable liquidliquid extractions from the reaction matrix. ${ }^{11}$ The process also allows the isolation of pure PPA $(8,94-98$ $\%$ purity) ${ }^{11}$ which is not possible when using the CHAI, Gilead or Laurus routes and was demonstrated on a 0.3 mol scale affording $87.6 \mathrm{~g}$ of PPA (8) with a purity $>94 \%{ }^{12}$ The route makes use of low cost reagents to afford the stage $2 \mathrm{~b}$ transformation, and is certainly more economical than the CHAI and Gilead routes, and competitive with the Laurus route. 


\section{Experimental section}

All reagents were purchased from Sigma Aldrich with the exception of adenine, RPA, DESMP and MTB which were purchased from Shenzhen Penking Biochemical Technology Co., Ltd.

Analytical analysis was performed on an Agilent 1200 HPLC with a flow-rate of $1 \mathrm{ml} / \mathrm{min}$ on a Waters Xbridge C18 (50 mm x $4.6 \mathrm{~mm} \times 5$ microns) coupled to a UV detector (260 nm) and an Agilent 6120 Quadrupole mass spectrophotometer in the positive mode. All purities are reported as HPLC area\% results with detection at $260 \mathrm{~nm}$. 1H NMR and 13C NMR data were recorded on a Bruker AVANCE III $400 \mathrm{MHz}$ spectrometer.

Preparation of (R)-9-(2-Hydroxypropyl)adenine (6). Adenine (4, 40 g, 296 mmol) and potassium hydroxide (1.66 g, $29.6 \mathrm{mmol}, 0.1$ equiv.) were mixed with $\mathrm{DMF}(190 \mathrm{~mL})$ at $25-30{ }^{\circ} \mathrm{C}$, the resulting mixture was stirred for $10 \mathrm{~min}$ at $25-30{ }^{\circ} \mathrm{C}$. $(R)$-propylene carbonate $(\mathbf{5}, 33.6 \mathrm{~mL}, 391 \mathrm{mmol}, 1.32$ equiv.) was added drop-wise to the reaction mass over $10-15 \mathrm{~min}$ at $25-30{ }^{\circ} \mathrm{C}$. The mixture was heated to $120{ }^{\circ} \mathrm{C}$ and held at that temperature for $2.5 \mathrm{~h}$. A clear solution resulted, and the reaction mixture was cooled to 70 ${ }^{\circ} \mathrm{C}$. A mixture of methanol $(30 \mathrm{~mL})$ and iso-propanol $(30 \mathrm{~mL})$ was added drop-wise to the reaction mixture over $10 \mathrm{~min}$, during which time the reaction mixture was cooled to $55^{\circ} \mathrm{C}$, and precipitation of product was observed. The reaction mixture was cooled to $\sim 5^{\circ} \mathrm{C}$ and held at this temperature for $1 \mathrm{~h}$. The product was isolated by filtration and the cake was washed with a chilled mixture of methanol $(10 \mathrm{~mL})$ and iso-propanol $(10 \mathrm{~mL})$. The resulting solid was dried under vacuum at $70-75^{\circ} \mathrm{C}$ affording (R)-9-(2hydroxypropyl)adenine (6) as an off-white solid (37 g, $65 \%$ yield, HPLC purity $98.5 \%) .{ }^{1} \mathrm{H}$ NMR (400 MHz, d6-DMSO) 8.14 (1H, s, Ar-H), $8.06(1 \mathrm{H}, \mathrm{s}, \mathrm{Ar}-\mathrm{H}), 7.20\left(2 \mathrm{H}, \mathrm{s}\right.$ broad, $\left.-\mathrm{NH}_{2}\right), 5.05\left(1 \mathrm{H}, \mathrm{d}, \mathrm{CH}_{2} \mathrm{CH}\right)$, 4.12-3.98 (3H, m, $\left.\underline{\mathrm{C}}_{2} \mathrm{CH}, \mathrm{CH}_{2} \mathrm{C} \underline{\mathrm{H}}, \mathrm{OH}\right), 1.07$ (3H, d, $\left.\underline{\mathrm{H}}_{3} \mathrm{CH}\right) .{ }^{13} \mathrm{C} \mathrm{NMR}(75 \mathrm{MHz}, \mathrm{d} 6-\mathrm{DMSO}) 155.78$, $152.22,149.55,141.32,118.48,64.60,50.00,20.78$.

Preparation of PPA (8). A mixture of HPA (6, $58 \mathrm{~g}, 300 \mathrm{mmol})$ and tert-butanol $(28.5 \mathrm{~mL}, 300 \mathrm{mmol}$, 1.0 equiv.) was suspended in cyclohexane $(300 \mathrm{~mL})$ under argon in a $2 \mathrm{~L}$ 3-necked round bottom flask fitted with an overhead stirrer. The suspension was charged with methyl magnesium chloride (3M in 
THF, $100 \mathrm{ml}, 300 \mathrm{mmol}, 1.0$ equiv.) which was added drop-wise at $0{ }^{\circ} \mathrm{C}$ to the rapidly stirring solution. The reaction mixture was stirred at $0{ }^{\circ} \mathrm{C}$ for $30 \mathrm{~min}$ before the drop-wise addition of DESMP $(7,193 \mathrm{ml}$, $750 \mathrm{mmol}, 2.5$ equiv.). The reaction mixture was heated at $75^{\circ} \mathrm{C}$ for $1 \mathrm{~h}$ after which time the reaction vessel was opened to boil off the cyclohexane, after $2-3 \mathrm{~h}$ HPLC indicated $>85 \%$ conversion. The resulting residue was dissolved in water $(170 \mathrm{~mL})$ and subjected to continuous extraction with chloroform ( $2 \mathrm{~L})$ for $24 \mathrm{~h}$. The organic phase was collected, dried $\left(\mathrm{Na}_{2} \mathrm{SO}_{4}\right)$, filtered and evaporated in vacuo to afford a yellow oil. HPLC indicated a mixture of HPA (6, $9.7 \%)$, PPA (8, 83.6 \%) and DESMP. The oil was taken up in dichloromethane $(300 \mathrm{~mL})$ and extracted with $2 \mathrm{M} \mathrm{HCl}(\mathrm{aq})(2 \times 150 \mathrm{~mL})$, the organic fraction was collected, dried $\left(\mathrm{Na}_{2} \mathrm{SO}_{4}\right)$, filtered and evaporated in vacuo to afford a mixture of unreacted DESMP (7) and the unidentified DESMP (7) by-product. ${ }^{11}$ The aqueous phase was basified to $\mathrm{pH} 11$ with $25 \%$ ammonia solution; the basified solution was extracted with dichloromethane $(3 \times 600 \mathrm{~mL})$. The combined organic phases were dried $\left(\mathrm{Na}_{2} \mathrm{SO}_{4}\right)$, filtered and evaporated in vacuo to afford PPA (8) as yellow oil which solidified to a white solid under vacuum (78.3 g, $76 \%$ yield, HPLC purity 94.3 \%). The aqueous phase was subjected to continuous extraction with dichloromethane $(250 \mathrm{~mL})$, the organic phase was isolated and evaporated in vacuo to afford a clear oil. HPLC indicated a mixture of HPA (6) and PPA (8). The organic phase was extracted with $2 \mathrm{M} \mathrm{HCl}(\mathrm{aq})(3 \times 200 \mathrm{~mL})$, the aqueous phase was basified to pH 11 using $25 \%$ ammonia solution; the basified solution was extracted with dichloromethane $(3 \times 200$ $\mathrm{mL})$. The combined organic phases were dried $\left(\mathrm{Na}_{2} \mathrm{SO}_{4}\right)$, filtered and evaporated in vacuo to afford PPA (8) as a yellow oil that solidified to a white solid under vacuum (9.3 g, $9 \%$, HPLC purity $97 \%)$. The combined batches afforded PPA (8) as a white solid (87.6 g, $85 \%$ yield). ${ }^{1} \mathrm{H}$ NMR (400 MHz, CDCl3) $8.34(1 \mathrm{H}, \mathrm{s}, \mathrm{Ar}-\mathrm{H}), 7.97(1 \mathrm{H}, \mathrm{s}, \mathrm{Ar}-\mathrm{H}), 5.80\left(2 \mathrm{H}, \mathrm{s}\right.$ broad, $\left.\mathrm{NH}_{2}\right), 4.36(1 \mathrm{H}, \mathrm{dd}, J=14.4 \mathrm{~Hz}$ and $J=7.7 \mathrm{~Hz}$ $\left.\mathrm{C}_{2} \mathrm{CH}\right), 4.00-4.18\left(5 \mathrm{H}, \mathrm{m}, 2\right.$ x $\left.\underline{\mathrm{C}}_{2} \mathrm{CH}_{3} \& \mathrm{C}_{2} \mathrm{CH}\right), 3.90-3.94\left(1 \mathrm{H}, \mathrm{m}, \mathrm{CHCH}_{3}\right), 3.55-3.86(2 \mathrm{H}, \mathrm{m}$, $\left.\mathrm{CH}_{2} \mathrm{P}\right), 1.30\left(3 \mathrm{H}, \mathrm{t}, J=7.1 \mathrm{~Hz}, \mathrm{C}_{3} \mathrm{CH}_{2}\right), 1.25\left(3 \mathrm{H}, \mathrm{t}, J=7.0 \mathrm{~Hz}, \underline{\mathrm{CH}}_{3} \mathrm{CH}_{2}\right), 1.24(3 \mathrm{H}, \mathrm{d}, J=6.2 \mathrm{~Hz}$, $\left.\mathrm{C}_{3} \mathrm{CH}\right) ;{ }^{13} \mathrm{C}$ NMR $\left(75 \mathrm{MHz}, \mathrm{CDCl}_{3}\right)$ 155.7, 152.6, 149.8, 141.3, 118.9, 76.13 (d, $\left.J=12.5 \mathrm{~Hz}\right), 63.39$ (d, $J=16.9 \mathrm{~Hz}), 62.13(\mathrm{~d}, J=6.6 \mathrm{~Hz}), 61.72(\mathrm{~d}, J=6.6 \mathrm{~Hz}), 47.90,16.29(\mathrm{~d}, J=5.8 \mathrm{~Hz}), 16.16,16.14(\mathrm{~d}, J$ $=5.8 \mathrm{~Hz})$. 
Preparation of (R)-(((Adenin-9-yl)propan-2-oxy)methyl)phosphonic Acid (3). PPA (8, 3 g, 8.74 mmol) was treated with $33 \% \mathrm{HBr} /$ Acetic Acid (6 mL, $59.6 \mathrm{mmol}, 6.82$ equiv.). The mixture was heated at $75^{\circ} \mathrm{C}$ while stirring for $3 \mathrm{~h}$. The reaction mixture was cooled to ambient temperature and diluted with water $(20 \mathrm{~mL})$. Ethyl acetate was added to the reaction mixture resulting in the precipitation of a cream solid which was removed by filtration. The $\mathrm{pH}$ of the solution was adjusted to $\sim \mathrm{pH} 3$ using $50 \% \mathrm{NaOH}$ (aq). The solution was cooled to $0{ }^{\circ} \mathrm{C}$ and stirred for $1 \mathrm{~h}$ during which time a white precipitate of PMPA (3) formed. The precipitate was collected by filtration through a sintered glass funnel affording PMPA (3) as a white solid (1.8 $\mathrm{g}, 67 \%$ yield).

\section{Acknowledgment}

We thank the Technology Innovation Agency (TIA) for financial support.

\section{Supporting Information Available}

\section{Supporting information}

HPLC information with representative chromatograms. This material is available free of charge via the Internet at http://pubs.acs.org.

\section{Corresponding Author}

* Darren Lyall Riley E-mail darren.riley@up.ac.za

\section{Present Addresses}

University of Pretoria, Department of Chemistry, Natural and Agricultural Sciences, 2 Lynnwood Road, Hatfield, 0002, Gauteng, South Africa 


\section{Author Contributions}

The manuscript was written through contributions of all authors. All authors have given approval to the final version of the manuscript.

\section{Funding Sources}

Technology Innovation Agency (TIA)

\section{References}

1. (a) Arimilli, M. N.; Kim, C. U.; Dougherty, J.; Mulato, A.; Oliyai, R.; Shaw, J. P.; Cundy, K. C.; Bischofberger, N. AntiViral Chem. Chemother. 1997, 8, 557. (b) Naessens, L.; Bischofberger, N.; Augustijns, P.; Annaert, P.; Van Den Mooter, G.; Arimilli, M. N.; Kim, C. U.; De Clerq, E. Antimicrob. Agents Chemother. 1998, 42, 1568. (c) Robbins, B. L.; Srinivas, R. V.; Kim, C.; Bischofberger, N.; Fridland, A. Antimicrob. Agents Chemother. 1998, 42, 612.

2. (a) Sax, P.E.; Zolopa, A.; Brar, I.; Elion, R.; Ortiz, R.; Post, F.; Wang, H.; Callebaut, C.; Martin, H.; Fordyce, M.W.; McCallister, S. J. Acquir. Immune Defic. Syndr. 2014, 67 (1), 52. (b) Markowitz, M.; Zolopa, A.; Squires, K.; Ruane, P.; Coakley, D.; Kearney, B.; Zhong, L.; Wulfsohn, M.; Miller, M.D.; Lee, W.A.; J Antimicrob Chemother 2014, 69, 1362.

3. (a) Ustianowski, A.;Arends, J.E.; Infect. Dis. Ther. 2015 (70). (b) Balzarini, J.; Holy, A.; Jindrich, J.; Naesens, L.; Snoeck, R.; Schols, D.; De Clerq, E. Antimicrob. Agents Chemother. 1993, 37, 332. 4. Srinivasan, R. (Gilead Sciences, Inc.) Combination therapy comprising tenofovir alafenamide hemifumarate and cobicistat for use in the treatment of viral infections WO2013116730 (A1), 2013. 5. Arimilli, M. N.; Cundy, K. C.; Dougherty, J. P.; Kim, C. U.; Oliyai, R.; Stella, V. J. (Gilead Sciences, Inc.) Antiviral phosphonomethyoxy nucleotide analogs having increased oral bioavarilability U.S. Patent $5,922,695,1998$.

6. Brown Ripin D.H.; Teager, D.S.; Fortunak, J.; Basha, S.M.; Bivins, N.; Boddy, C.N.; Byrm, S.; Catlin, K.K.; Houghton, S.R.; Jagadeesh, S.T.; Kumar, K.A.; Melton, J.; Muneer, S.; Rao, L.: Rao, R.V.; Ray, 
P.C.; Reddy, N.G.; Reddy, R.M.; Shekar, K.C.; Silverton, T.; Smith, D.T.; Stringham, R.W.; Subbaraju, G.V.; Talley, F.; Williams, A.; Org. Process Res. Dev.2010, 14, 1194.

7. Select examples include (a) Vasireddy, U.M.R.; Vellanki, S.R.P.; Balusu, R.B.; Bandi, N.D.R.; Jujjavarapu, P.K.; Ginjupalli, S.R.; Pilli, R.K. (Matrix Laboratories Ltd) WO2008007392 A2. Process for the preparation of tenofovir (b) Indukuri, V.S.K.; Joga, S.R.; Gorantla, S.R.; Chava, S. (Laurus Labs Private Limited) Process for the preparation of tenofovir WO2013072745 A1 (c) Datta, D.; Rama, S.; Vandali, L.R.; Gorantla, S.S.C.; Da Sari, S.R.; Mittapelly, N.; Vellanki, S.R.P.; Sahu, A.; Balusu, R.B.; Ravi, M.R.; Nandipati, H.B. (Matrix Laboratories Ltd) An improved process for the preparation of tenofovir disoproxil fumarate, WO2011111074.

8. Select examples include (a) Czarnik, A. (Czarnik Anthony, Protia Llc) Deuterium-enriched tenofovir WO2008157657.; (b) Holy, A.; Dvorakova, H.; Desire, E.; De Clercq, A.; Balzarini, J.M.R. (Institute of Organic Chemistry And Biochemistry Of The Academy Of Science Of The Czech Republic, Rega Stichting V.Z.W.) Antiretroviral enantiomeric nucleotide analogs, US6653296 B1.

9. Select examples include (a) Barral, K.; Priet, S.; Sire, J.; Neyts, J.; Balzarini, J.; Canard, B.; Alvarez, K.; J. Med. Chem. 2006, 49 (26), 7799. (b) Munger Jr, J.D.; Rohloff, J.C.; Schultze, L.M. (Gilead Sciences Inc.) Nucleotide analog composition and synthesis method WO1999005150 A1. 10. Select examples include (a) Satyanarayana, C.; Ramanjaneyulu, G.S.; Kumar, I.V.S.; Rambabu, J.S. (Laurus Labs Private Limited) Process for the preparation of tenofovir EP2462935(A1), 2012. (b) Larrow, J.F.; Schaus S.E., Jacobsen, E.N.; J. Am. Chem. Soc., 1996, 118 (31), 7420. (c) Schultze, L.M.; Chapman, H.H.; Dubree, N.J.P.; Jones, R.J.; Kent, K.M.; Lee, T.T.; Louie, M.S.; Postich, M.J.; Prisbe, E.J.; ROhloff, J.C.; Yu, R.H.; Tetrahedron Lett., 1998, 1853. (d) Chavakula, R.; Mutyala, N.; Chennupati, S.; Org. Chem. Ind. J. 212, 8 (11), 232.

10. When performed in NMP a gel forms on heating the reaction mixture prior to the addition of the $\operatorname{DESMP}(7)$, this typically occurs between 50 and $70{ }^{\circ} \mathrm{C}$.

11. The DESMP by-product refers to what appeared to be de-tosylated DESMP (7) the MS was consistent with $(\mathrm{HO}) \mathrm{CH}_{2} \mathrm{PO}(\mathrm{OEt})_{2}$ however we were unable to isolated and further characterize the species. 
12. It should be noted that the "pure" PPA (8) always contains a trace amount of HH-PPA (9) in the range of $1-2 \%$. For ease of reading we simply refer to the product as being pure PPA $(\mathbf{8})$ to show the total conversion or isolated yield as both the PPA (8) and HH-PPA (9) are converted into PMPA (3) in Stage 2b. HPLC purities therefore refer to the sum of the area $\%$ for both the PPA (8) and HH-PPA (3) 